\title{
Antimetastatic Effect of Triton WR 1339, a Nonionic Detergent, on Rat Ascites Tumors
}

\author{
Kunihisa Hashimoto, Senji Miura and Chigashi Suzuki \\ Department of Surgery, the Research Institute for Chest \\ Diseases and Cancer, Tohoku University, Sendai 980
}

\begin{abstract}
Hashimoto, K., Mrura, S. and Suzuki, C. Antimetastatic Effect of Triton WR 1339, a Nonionic Detergent, on Rat Ascites Tumors. Tohoku J. exp. Med., 1979, 128 (3), 259-265 — The antimetastatic effect of Triton WR 1339 (TWR), a nonionic detergent, was evaluated in the rats bearing ascites tumor (Yoshida sarcoma or AH 66F). TWR did not inhibit the growth of primary tumor (ascites production). However, a marked inhibition of metastasis was observed in the lung and liver of rats treated with TWR. The results obtained suggest that TWR exerts antimetastatic effect before the entry of tumor cells into vascular channels. With other tests, it was found that TWR inhibits the release of tumor cells from tumor graft.— Triton WR 1339; nonionic detergent; metastasis; ascites tumors
\end{abstract}

Recently several experiments have been carried out with the drugs which selectively inhibit the dissemination of tumor cells but have no effects on primary growth (Rosso et al. 1969; Burrage et al. 1970; Franchi et al. 1971; Le Serve and Hellmann 1972; Atherton et al. 1975; Giraldi et al. 1977).

With several strains of tumor, most rats die within about 10 days after the intraperitoneal inoculation of ascites cells isolated from rats. In these rats, there are always microscopic metastases in the liver and in the lung (Hashimoto and Sato 1963). Therefore, when the peritoneal cavity is inoculated with a strain of tumor as the primary site of growth, drugs which inhibit the dissemination of tumor can be selected easily during a short period of time by microscopic examinations of the lung and/or liver.

The present communication is concernced with the experiments which were carried out to study the antimetastatic effect of Triton WR 1339 (non-ionic detergent) on dissemination of tumor.

\section{Materials and Methods}

Male Donryu Rats weighing about $100 \mathrm{~g}$ were obtained from Nippon Rats Co., Tokyo. Yoshida sarcoma, ascites tumor AH66F and AH109A were supplied from the department of Oncology of this Institute. The tumors were maintained through serial transplantation in Donryu rats.

Received for publication, August 9, 1978.

This work was supported in part by a Grant-in Aid for Cancer Research from the Ministry of Health and Welfare, Japan, and by a Grant-in-Aid for Fundamental Scientific Research from the Ministry of Education, Science and Culture, Japan. 
Triton WR 1339 (TWR), a formaldehyde polymer of polyxyethylene ether of octylphenol (Roland Am. Corporation, USA.), was diluted with sterile physiological saline to a final concentration of $50 \mathrm{mg} / 0.1 \mathrm{ml}$.

\section{Results}

\section{Effect of TWR on lung and liver metastasis}

Rats were inoculated intraperitoneally with $10^{6}$ tumor cells of Yoshida sarcoma or AH66F. From the next day on, the rats received TWR injections at a dose of $500 \mathrm{mg}$ per $\mathrm{kg}$ body weight daily for 4 days i.p. or i.v. Before the rats were sacrificed on the 6th day after the inoculation, the ascites and $1 \mathrm{ml}$ of the blood from the right ventricle were collected aseptically for the bioassay of tumor cells. The samples from one donor were inoculated i.p. in two recipients. All the sacrificed rats were subjected to gross examination and fixed in a neutralized $10 \%$ solution of formalin. The lungs and the livers were processed in a usual manner for histological examination and the sections were stained with hematoxylin and eosin.

Table 1 shows the results of the bioassay for tumor cells in the ascites and in the blood from the right ventricle collected aseptically. The rate of takes of the ascites was $100 \%$ irrespective of the routes of TWR injection. This indicates that TWR had no cytocidal effects on the tumor cells in ascites. However, the rate of takes with the blood from the right ventricle was different depending on the routes of treatment with TWR. The rate of takes was about $30 \%(5 / 16)$ in the recipients inoculated with the blood from i.p.-treated donors and $50 \%$ in those with the blood from i.v.-treated donors. The rate of takes was $100 \%$ in the recipients inoculated with the blood of the saline treated donors. Thus it was found that TWR had no cytocidal effect on tumor cells. The results described above indicate that the i.p.injection of TWR caused a marked decrease of tumor cells in the blood.

TABLE 1. Bioassay for tumor cells in ascites and in right ventricle blood $(R V B)$ collected at autopsy

\begin{tabular}{|c|c|c|c|c|c|c|}
\hline \multirow[b]{2}{*}{ Tumor } & \multirow{2}{*}{$\begin{array}{l}\text { Number of } \\
\text { animals } \\
\text { inoculated }\end{array}$} & \multirow{2}{*}{$\begin{array}{l}\text { Route of } \\
\text { injection }\end{array}$} & \multicolumn{4}{|c|}{ Number of recipients } \\
\hline & & & $\begin{array}{l}\text { Inoculated } \\
\text { with ascites }\end{array}$ & With takes & $\begin{array}{l}\text { Inoculated } \\
\text { with RVB }\end{array}$ & With takes \\
\hline \multirow{4}{*}{$\begin{array}{l}\text { Yoshida } \\
\text { sarcoma }\end{array}$} & 8 & ip (TWR) & 16 & 15 & 16 & 5 \\
\hline & 10 & ip (saline) & 20 & 20 & 20 & 20 \\
\hline & 10 & iv (TWR) & 20 & 20 & 20 & 10 \\
\hline & 10 & iv (saline) & 20 & 20 & 20 & 20 \\
\hline \multirow[t]{4}{*}{$\mathrm{AH} 66 \mathrm{~F}$} & 10 & ip (TWR) & 20 & 16 & 20 & 6 \\
\hline & 10 & ip (saline) & 20 & 20 & 20 & 20 \\
\hline & 10 & iv (TWR) & 20 & 20 & 20 & 12 \\
\hline & 10 & iv (saline) & 20 & 20 & 20 & 20 \\
\hline
\end{tabular}

One million tumor cells of Yoshida sarcoma or AH66F were i.p. inoculated into the rats. From the next day on, the rats received for 5 days the injection of TWR in a dose of $500 \mathrm{mg}$ per $\mathrm{kg}$ body weight by i.p. or i.v. route. The rats were sacrificed on the 6 th day after inoculation. Bioassay was made for tumor cells in the ascites and blood from the right ventricle. 
The histologcial examination revealed that there were marked metastases both in the lung and in the liver of the saline treated. In the lung, there was an extensive growth of tumor cells in the perivascular spaces. Also emboli of numerous cells were observed in the capillaries (Fig. 1). In the liver of these animals, tumor cells were found everywhere in sinusoids and around the central or portal veins (Fig. 2) On the other hand, in the animals given TWR i.p. metastatic foci were only scarcely found in the lung (Fig. 3) and in the liver (Fig. 4). Even when metastases were

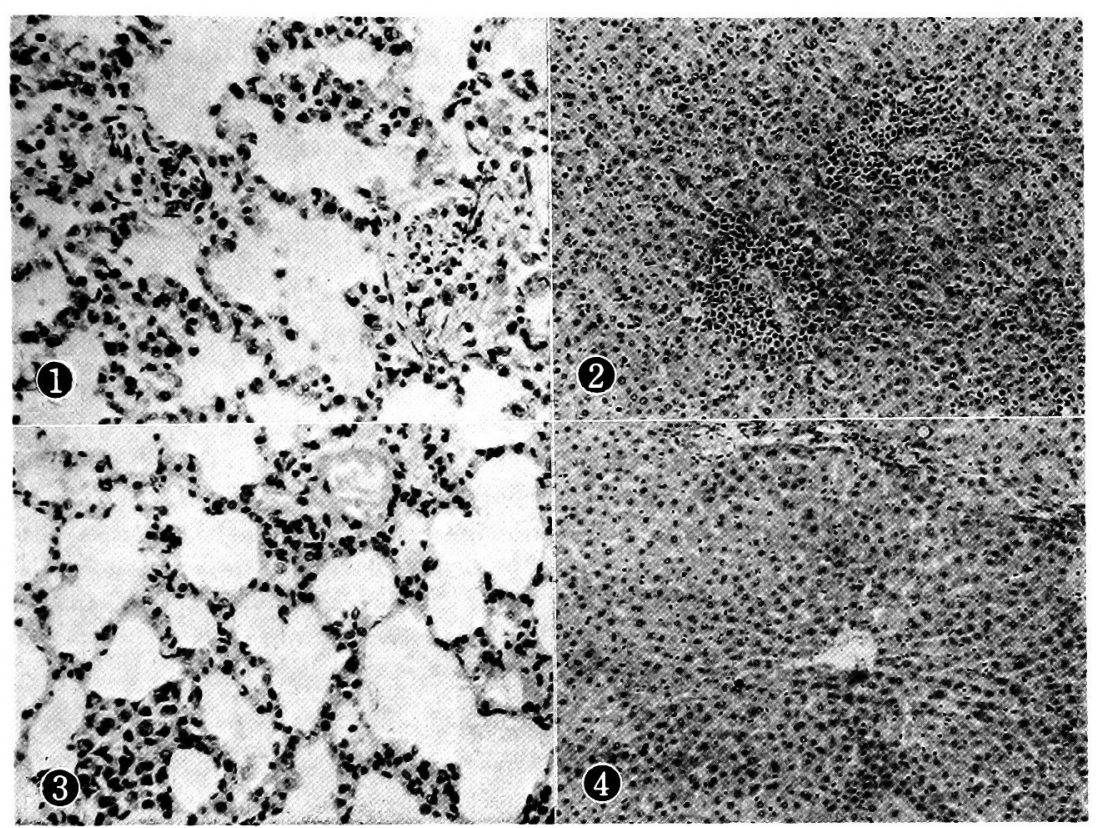

Fig. 1. Lung of the saline treated rat. Emboli of tumor cells in the capillaries of alveoli and growth of tumor cells are observed in the perivascular spaces.

Fig. 2. Liver of the saline treated rat. Numerous metastatic foci and tumor cells are scattered around the central veins and in the sinusoids.

Fig. 3. Lung of the rat given TWR i.p. One localized metastatic lesion is noted.

Fig. 4. Liver of the rat given TWR i.p. Only a few tumor cells are observed.

found, there was a tendency to form localized foci (Fig. 3). These findings indicate the reduction in number of tumor cells in the blood of rats given TWR i.p. and are in agreement with results of bioassay for tumor cells in the blood from the right ventricle. The results obtained suggested, in view of the lack of cytocidal action of TWR on tumor cells, that the low rate of takes of the blood from animals given TWR i.p. is due to the reduction in number of tumor cells in the blood. Presumably TWR acts on tumor cells before they enter the vascular channels and thus the number of tumor cells in the blood decreases. 
Effect of TWR administration before inoculation of tumor cells on dissemination of tumor cells

In order to examine whether the administration of TWR before inoculation of tumor cells causes any change in the dissemination of tumor cells, following experiments were carried out. One group of 10 rats received i.v. administration of TWR for 4 days before tumor inoculation. Thereafter, AH66F was inoculated i.p. in both groups. Both groups were then kept under observation without TWR administration. The rats were sacrificed on the 5th day after inoculation and the lung and liver were subjected to microscopic examination. Table 2 shows a markedly reduced metastasis in the group which received the i.p. administration of TWR. The result suggests that a condition favorable for the inhibition of metastasis was created in the rats by the i.p. administration of TWR.

TABLE 2. Effect of TWR administered before $A H 66 F$ inoculation on metastasis

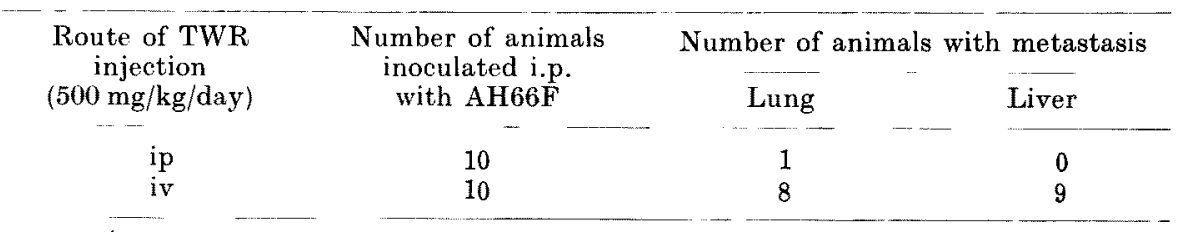

TWR was injected i.p. in 10 rats and injected i.v. in another 10 rats in a dose of $500 \mathrm{mg} / \mathrm{kg} /$ day for 4 days. Thereafter AH66F was inoculated i.p. Without the administration of TWR, the rats were sacrificed on the 5th day after inoculation. The lung and liver were subjected to microscopic examination.

\section{Effect of TWR on release of tumor cells from tumor graft}

As the results described above suggested that TWR inhibited the release of tumor cells from the primary growth, an experiment was made on the effect of TWR on the release of tumor cells from tumor graft using the solid tumor transplanted subcutaneously.

AH109A cells $\left(5 \times 10^{6}\right)$ were inoculated subcutaneously into the back of 60 rats. They were divided into three groups of 20 animals each. Except for one group which served as a control, TWR was injected at a dose of $500 \mathrm{mg}$ per $\mathrm{kg}$ body weight for 9 consecutive days either i.p. or i.v. route from the next day. A $5 \mathrm{~mm}^{3}$ tumor graft was taken from each animal on the 10th day after inoculation. The tumor fragment, $1 \mathrm{ml}$ of physiological saline solution and 15 glass beads of $3 \mathrm{~mm}$ in diameter were shaken in a $5 \mathrm{ml}$ Erlenmyer flask for $15 \mathrm{~min}$ on a blood cellpipette shaker. Then the physiological saline solution was withdrawn and the number of tumor cells in the solution was counted in a hemocytometer. Fig. 5. shows that the average number of tumor cells was different depending on the routes of TWR administration. The number of cells in the saline was larger in the following order: the i.p.-treated group, the i.v.-treated group and the control. Thus it is unlikely that the tumor cells are liberated more easily from the grafts after the 
i.p. administration of TWR. TWR may facilitate the aggregation of cells in tumor fragments and prevent the cells from being liberated.

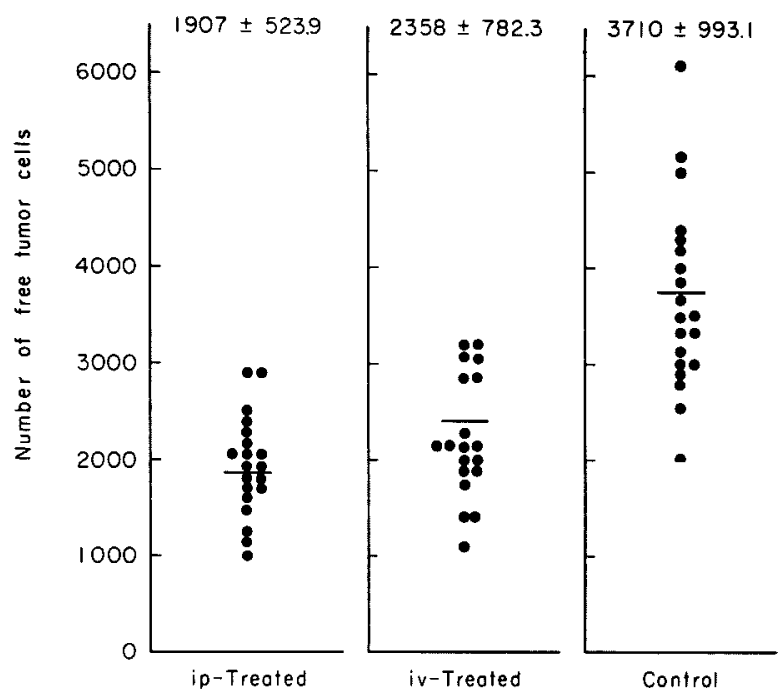

Fig. 5. Effect of TWR on release of free tumor cells from tumor graft.

* Mean \pm s.D. $(n=20)$. The number of tumor cells in the i.p.-treated group is significantly smaller than in the control $(p<0.01)$.

\section{Discussion}

Treatment of cancer would be made much easier if measures could be found to control the systemic spread. For this reason studies have been made on the drugs which prevent the dissemination of tumor cells selectively (Rosso et al. 1969; Burrage et al. 1970; Franchi et al. 1971; Le Serve and Hellmann 1972; Atherton et al. 1975; Giraldi et al. 1977). It was reported that Triton WR 1339 may interfere with the lodgement of tumor cells and thus inhibit the metastatic spread (Rosso et al. 1969; Franchi et al. 1971). Le Serve and Hellmann (1972) reported that inhibition of metastasis by ICRF 159 is due to the poor angiogenesis at the margins of a primary tumor.

On the other hand it has been reported that TWR induces hyperlipemia in animals (Friedman and Byers 1953). The study of Cliffton and coworkers (1961) showed that hyperlipemia facilitated the lodgement of tumor cells. From these reports it is conceivable that TWR may facilitate metastasis. These results are in disagreement with the present observations which indicated that TWR acts on the step related to the release of tumor cells from the primary tumor and before the entry of tumor cells into vascular channels. This hypothesis was substantiated by the microscopic findings in the liver and lung of the intraperitoneally treated animals. The tests on the effect of TWR indicated that TWR administration inhibited the release of tumor cells from the fragments. It is likely 
that the detergent action of TWR changes the property of the membrane of tumor cells and results in the increase of mutal adhesiveness of tumor cells. In this connection, it is of interst to note that hypervitaminosis A facilitated the release of cells from the primary tumor by releasing lysosomal enzyme and resulted in an increase of metastatic foci (Wexler et al. 1965).

In the present experiment, a marked inhibition of metastasis was noted only in the animals which received the i.p. administration of TWR before the i.p. inoculation of tumor cells. This result suggests that a condition favorable for the inhibition of metastasis was created in the host after i.p. administration of TWR. Currie and Sime (1973) showed that syngeneic immune serum inhibited the in vitro movement of lymphoma cells. It has been demonstrated that the development of metastases was inhibited by specific humoral factors (Fisher and Fisher 1961; Proctor et al. 1973). Also there is evidence indicating that the treatment with trypanblue or TWR before inoculation of tumor activates the phagocytic activity of the host (Mahaley and Kniaely 1959; Franchi et al. 1971)

The present investigation illustrates the possibility that there is an interaction between dissemination of tumor cells and reaction of the host. Further investigations on the host factors are important in order to establish the effective measures to control dissemination of tumors.

\section{References}

1) Atherton, A., Busfield, D. \& Hellmann, K. (1975) The effects of an antimetastatic agent, ( \pm )-1,2-Cis (3,5-dioxopiperazin-1-yl) propane (ICRF 159), on platelet behavior. Cancer Res., 35, 953-957.

2) Burrage, K., Hellmann, K. \& Salsbury, A.J. (1970) Drug-induced inhibition of tumor cell dissemination. Brit. J. Pharmacol., 39, 205.

3) Cliffton, E.E., Agostino, D. \& Minde, K (1961) The effect of hyperlipemia on pulmonary metastases of Walker 256 carcinosarcoma in the rat. Cancer Res., 21, 1062-1072.

4) Currie, G.A. \& Sime, G.C. (1973) Syngeneic immune serum specifically inhibits the motility of tumor cells. Nature (Lond.) New Biol., 241, 284-285.

5) Fisher, E.R. \& Fisher, B. (1961) Experimental studies of factors influencing hepatic metastases, VII. Effect of reticulo-endothelial interference. Cancer Res., 21, 275-280.

6) Franchi, G., Morsca, C., Reyers-Degli-Zunocenti, I. \& Garattini, S. (1971) Triton WR1339 (TWR), an inhibitor of cancer dissemination and metastases. Europ. J. Cancer, 3, 533-544.

7) Friedman, M. \& Byers, S.O. (1953) The mechanism responsible for the hypercholesterolemia induced by Triton WR 1339. J. exp. Med., 97, 117-130.

8) Giraldi, T., Nisi, C. \& Sava, G. (1977) Brief communication: Antimetastatic effects of N-Diazoacetyl-glycine derivatives in C 57 BL mice. J.nat. Cancer Inst., 58, $1129-1130$.

9) Hashimoto, K. \& Sato, H. (1963) Studies on metastasis of cancer XII, Tumor spread of the rat ascites hepatomas, Proceedings of 22nd General Meeting of the Japanese Cancer Association, p. 267. (Japanese)

10) Le Serve, A.W. \& Hellmann, K. (1972) Metastases and normalization of tumor blood vessels by ICRF 159; A new type of drug action. Brit. med. J., 1, 597-600.

11) Mahaley, M.S., Jr. \& Kniaely, W.H. (1959) Effect of trypanblue upon distribution of metastases and transplanted rabbit $\mathrm{VX}_{2}$ and Walker rat 256 tumor. Cancer Res., 19, 627-632. 
12) Proctor, J.W., Rudenstarn, C.M. \& Alexandar, P. (1973) A factors preventing the development of lung metastases in rats with sarcomas. Nature (Lond.) New Biol., 242, 29.

13) Rosso, R., Donelli, M.G., Franchi, G. \& Garattini, S. (1969) Effect of Triton WR 1339 on cancer dissemination and metastases. Europ. J. Cancer, 5, 77-78.

14) Wexler, H., Minton, J.P. \& Ketcham, A.S. (1965) A comparison of survival time and extent of tumor motastasis in mice with transplanted, induced and spontaneous tumors. Cancer, 18, 985-994. 